\title{
RESEARCH
}

Open Access

\section{Understanding effects in reviews of implementation interventions using the Theoretical Domains Framework}

\author{
Elizabeth A. Little, Justin Presseau ${ }^{*}$ and Martin P. Eccles
}

\begin{abstract}
Background: Behavioural theory can be used to better understand the effects of behaviour change interventions targeting healthcare professional behaviour to improve quality of care. However, the explicit use of theory is rarely reported despite interventions inevitably involving at least an implicit idea of what factors to target to implement change.

There is a quality of care gap in the post-fracture investigation (bone mineral density (BMD) scanning) and management (bisphosphonate prescription) of patients at risk of osteoporosis. We aimed to use the Theoretical Domains Framework (TDF) within a systematic review of interventions to improve quality of care in post-fracture investigation. Our objectives were to explore which theoretical factors the interventions in the review may have been targeting and how this might be related to the size of the effect on rates of BMD scanning and osteoporosis treatment with bisphosphonate medication.
\end{abstract}

Methods: A behavioural scientist and a clinician independently coded TDF domains in intervention and control groups. Quantitative analyses explored the relationship between intervention effect size and total number of domains targeted, and as number of different domains targeted.

Results: Nine randomised controlled trials (RCTs) (10 interventions) were analysed. The five theoretical domains most frequently coded as being targeted by the interventions in the review included "memory, attention and decision processes", "knowledge", "environmental context and resources", "social influences" and "beliefs about consequences". Each intervention targeted a combination of at least four of these five domains. Analyses identified an inverse relationship between both number of times and number of different domains coded and the effect size for BMD scanning but not for bisphosphonate prescription, suggesting that the more domains the intervention targeted, the lower the observed effect size.

Conclusions: When explicit use of theory to inform interventions is absent, it is possible to retrospectively identify the likely targeted factors using theoretical frameworks such as the TDF. In osteoporosis management, this suggested that several likely determinants of healthcare professional behaviour appear not yet to have been considered in implementation interventions. This approach may serve as a useful basis for using theory-based frameworks such as the TDF to retrospectively identify targeted factors within systematic reviews of implementation interventions in other implementation contexts.

Keywords: TDF, Behaviour change interventions, Systematic review, Osteoporosis, Fragility fracture, BMD scanning, Bisphosphonates, Secondary analysis

\footnotetext{
* Correspondence: justin.presseau@ncl.ac.uk

Institute of Health and Society, Newcastle University, Baddiley-Clark Building,

Richardson Road, Newcastle Upon Tyne NE2 4AX, UK
} 


\section{Background}

Changing the behaviour of healthcare professionals is key to achieving the goals of evidence-based medicine, ensuring that research findings are translated into clinical practice and the best possible outcomes for patients are realised. This is not an easy task to carry out systematically, routinely and uniformly, but it has been shown to be more effective if interventions are based on evidencebased principles drawn from theories of behaviour and behaviour change $[1,2]$.

Theory can be used prospectively to identify and describe the processes involved in existing patterns of care and the barriers and facilitators to change that could be targeted by an intervention [3, 4]. Theory can then be used to guide the development and content of the intervention, giving an understanding of how and why the intervention is designed to work and a framework for testing the mechanism(s) underlying behaviour change [5-7]. The explicit use of theory in this way not only provides a generalizable framework facilitating the replication of interventions in other settings [8], but there is also evidence that behaviour change interventions informed by theory are more effective than those that are not $[1,2,9]$. Despite increasing recognition that the design of behaviour change interventions should be based on relevant theories $[8,10,11]$, systematic reviews of behaviour change interventions applied to change the behaviour of healthcare professionals show that theory is rarely used to explicitly underpin intervention methods [12]. Thus, even if positive effects are reported, we are left with little understanding of the behaviour change processes responsible, no basis for choosing between different types of intervention, and little to inform the design of future interventions.

Although interventions may not always be based on a theory explicitly, it is inevitable that any intervention designer will have at least an implicit idea of what factors to target to promote change. Such implicit theories may be helpful for the specific setting in which they are used, but without making them explicit, they cannot be tested and replicated. Given the likely preponderance of implicit theories, it may be useful to retrospectively identify which factors implementation interventions report targeting and the extent to which such factors map onto pre-existing theoretical factors. Such a process would be inferential but would nevertheless provide a better capacity to identify what factors seem to be targeted and thus contribute to a cumulative evidence base for designing future interventions.

Retrospective coding of targeted factors requires a sufficiently broad framework of theoretical factors to capture the potential range of possible targeted factors. The Theoretical Domains Framework (TDF) [13] was developed and validated [14] to summarise the array of psychological theory underpinning behaviour change into distinct factors.
The TDF provides a useful basis for both assessing implementation problems and for identifying potential modifiable factors to target when designing interventions [15]. It is increasingly used as a tool for conducting interviews and designing questionnaires [16-20], but it may also be used as a basis for understanding what factors may have been targeted for change in an intervention. This has the potential to enhance understanding of the behaviour change processes inherent in the transfer of evidencebased guidelines into practice, but to our knowledge, the TDF has yet to be applied in this way. Using the clinical setting of post-fracture investigation and management of patients at risk of osteoporosis, we aimed to conduct a secondary analysis of a systematic review using the TDF to identify the factors targeted by the interventions.

\section{Post-fracture management of osteoporosis risk}

The post-fracture management of patients at risk of osteoporosis is an area of patient care in which there is evidence of a large quality of care gap [21-30] despite widely available evidence-based guidelines [31-35]. Two key post-fracture management behaviours for which a quality gap has been widely documented include primary and secondary healthcare professionals scanning bone mineral density and prescribing anti-resorptive therapy.

We conducted a systematic review of interventions (reported elsewhere) [36] aiming to improve the investigation and management of osteoporosis in patients following fragility fracture. For both of the main outcomes of the review (bone mineral density (BMD) scanning and osteoporosis treatment with anti-resorptive therapy), all nine identified studies [37-45] reported a positive effect of the intervention, with an overall $36 \%$ absolute increase in BMD scanning rates and a $20 \%$ absolute increase in treatment rates.

Whilst the review provided a compelling case that implementation interventions can be effective in improving scanning and treatment rates, replicability of these interventions is undermined by a lack of capacity to understand how the intervention had its effect, i.e. what factors did the interventions target to promote change.

The aim of this paper was to explore, using the TDF, the factors that the interventions may have been targeting, how this might be related to the main outcomes of the systematic review (rates of BMD scanning and osteoporosis treatment with bisphosphonate medication) and highlighting opportunities for targeting factors that seem to be less frequently considered but may be worth exploring in future interventions.

\section{Methods}

\section{Description of interventions}

As part of the systematic review, a verbatim description of the interventions as delivered and the care received by the control group was extracted and reported. The 
authors of the studies included in the systematic review were contacted by email and informed of our intention to carry out a secondary analysis of their interventions. It was requested in the email that firstly they verify whether or not they agreed with the details of their intervention which were identified and described in the email and secondly send us any additional materials that were given to those delivering the intervention or any protocols or linked studies that described the intervention, how it was carried out and what it was targeting, in more detail. Those nominated as the corresponding author were contacted initially, but if the email address was no longer functioning, alternative authors were tried. A first reminder was sent 2 weeks after the initial email, a second reminder 2 weeks after that, and the authors were then given a further 2 weeks to respond.

\section{Coding of the TDF domains targeted by the interventions}

We used the 14 domains from TDFv2 [14] as a basis for coding TDF domains. The TDF domains that appeared to be targeted by the interventions and within the control groups were identified and coded independently by two reviewers (EAL, a clinician and JP, a behavioural scientist), using a data extraction form designed for the purpose (Additional file 1). We used domains as well as constructs within domains to inform coding decisions within domains, using construct definitions as described by Cane et al. [14]. The data extraction form was tested on one included study. The coding of each domain was supported by evidence from the text. However, this required inferences to be made about which domains the authors were intending to target, as this was never explicitly stated in the text. The descriptions of the interventions were studied and each aspect that was judged to be targeting a domain with respect to the behaviours of BMD scanning and osteoporosis treatment with antiresorptive medication was coded. The domains were also coded according to the individual targeted, i.e. patient or healthcare professional. Inter-rater reliability was calculated prior to resolving discrepancies (Cohen's kappa: $K=0.507$ (moderate agreement [46]). Following discussion with a third party (MPE), $100 \%$ agreement was achieved.

\section{Quantitative analysis}

The relationship between the total number of domains coded and effect size of the intervention was explored using Pearson correlations (two-tailed) for both BMD scanning and osteoporosis treatment with anti-resorptive therapy. "Total number of domains" is a sum of every time any domain was coded and does not take into account the recipient of the intervention. For example, if "knowledge" was coded twice for the primary care physician (PCP) and once for the patient, and "beliefs about consequences" was coded three times for the PCP, this would add up to a total of six times. The total number of times the domains were coded in the control groups of the studies was subtracted from the total number of times the domains were coded in the intervention groups. This was a subtraction of total number of domains and did not take into consideration which domains were coded in each group. To investigate whether subtracting domains that appear in the control group impacted on the findings, we conducted a sensitivity analysis whereby all domains coded in the intervention group were counted irrespective of whether also coded in the control group.

The relationship between the number of different domains coded and the effect size of the intervention was also explored using Pearson correlations for both BMD scanning and osteoporosis treatment with antiresorptive therapy. The recipient of the intervention was not taken into account. For example, if "knowledge" was coded five times, "skills" once and "social influence" twice, this would mean that three different domains had been coded. The maximum possible number of different domains coded was 14 (the number of TDF domains). The number of different domains coded in the control group was subtracted from the number of different domains coded in the intervention group. A sensitivity analysis was performed in which the subtraction of control groups was not done, to examine the effect of the subtraction on the result.

\section{Results}

\section{Descriptions of the interventions and control care}

With regard to the development of the intervention, only two studies reported consulting with representatives of the intended professional recipients [40, 43]. Six studies reported the evidence base for the intervention [37, 38, 40-43]. Patient involvement was not reported by any of the studies. In four studies, the authors reported specific barriers to change that the intervention was tailored to address [37, 40, 42, 44]. Only one study reported that they had carried out substantial exploratory work to identify them [40] (literature reviews and qualitative in-depth interviews with healthcare professionals). In two of the four studies, barriers were not identified and discussed until the end of the paper [37, 44]. Only one study designed the intervention to address all of the identified barriers [40]; the others offered no explanation as to why they had chosen particular barriers to target over others, with one study selecting a single barrier from a long list of barriers [44].

The coding for the domains targeted in the intervention and control groups for each of the studies is shown in Table 1. A more detailed description of the coding as well as the care given to intervention and control groups by study is presented in Additional file 2. 
Table 1 Coding of domains targeted in the intervention and control groups

\begin{tabular}{|c|c|}
\hline Study & Intervention group: domains targeted \\
\hline \multirow[t]{10}{*}{ Gardner 2005} & Patient \\
\hline & - Knowledge (knowledge from 15-min educational visit) \\
\hline & - Beliefs about consequences ( $T$ : effectiveness of therapies) \\
\hline & $\begin{array}{l}\text { - Environmental context and resources (material resource } \\
\text { of questions) }\end{array}$ \\
\hline & $\begin{array}{l}\text { - Memory, attention and decision processes (attention } \\
\text { from telephone call at } 6 \text { weeks) }\end{array}$ \\
\hline & $\begin{array}{l}\text { - Beliefs about consequences (call may have targeted } \\
\text { beliefs about consequences of seeking follow-up with PCP }\end{array}$ \\
\hline & PCP \\
\hline & - Goals (questions are goals and action plans) \\
\hline & $\begin{array}{l}\text { - Memory, attention and decision processes (questions } \\
\text { focus attention) }\end{array}$ \\
\hline & $\begin{array}{l}\text { - Memory, attention and decision processes } \\
\text { (attention from patient attending to discuss } \\
\text { management of osteoporosis) }\end{array}$ \\
\hline
\end{tabular}

PCP

- Knowledge (knowledge from guidelines)

- Memory, attention and decision processes (attention from EMR)

- Social influences (message from chairman acts as social influence)

- Environmental context and resources (permanent record is a resource)

- Memory, attention and decision processes (attention from second message)

Intervention 2

PCP

- Knowledge (knowledge from guidelines)

- Memory, attention and decision processes (attention from EMR)

- Social influences (message from chairman acts as social influence)

- Environmental context and resources (permanent record is a resource)

- Memory, attention and decision processes (attention from second message)

- Memory, attention and decision processes (copy of patient letter sent to PCP focuses attention as PCP aware patient may visit for discussion)

- Memory, attention and decision processes (attention from patient attending to discuss management options)

- Memory, attention and decision processes (decision processes: patient attending to discuss management options)

Patient

- Knowledge (knowledge from educational materials)

- Memory, attention and decision processes (attention from letter to patient to discuss management options with $\mathrm{PCP}$ )

- Social influences (person sending letter to patient may act as a social influence if this is chairman as for PCPs)

None identified 
Table 1 Coding of domains targeted in the intervention and control groups (Continued)

\begin{tabular}{|c|c|}
\hline \multirow[t]{9}{*}{ Davis 2007} & Patient \\
\hline & - Knowledge (knowledge from osteoporosis information) \\
\hline & $\begin{array}{l}\text { - Memory, attention and decision processes } \\
\text { (S: attention from letter encouraging patient } \\
\text { to return to PCP) }\end{array}$ \\
\hline & $\begin{array}{l}\text { - Environmental context and resources (S: material } \\
\text { resource of letter to take to } \mathrm{PCP} \text { ) }\end{array}$ \\
\hline & $\begin{array}{l}\text { - Memory, attention and decision processes } \\
\text { (attention from telephone call at } 3 \text { months) }\end{array}$ \\
\hline & PCP \\
\hline & $\begin{array}{l}\text { - Memory, attention and decision processes } \\
\text { (S: attention from letter) }\end{array}$ \\
\hline & $\begin{array}{l}\text { - Memory, attention and decision processes } \\
\text { (S: attention from patient attending for further } \\
\text { investigation) }\end{array}$ \\
\hline & $\begin{array}{l}\text { - Social influences (S: social influence of } \\
\text { orthopaedic surgeon) }\end{array}$ \\
\hline \multirow[t]{9}{*}{ Majumdar 2007} & Patient \\
\hline & $\begin{array}{l}\text { - Knowledge (knowledge from educational } \\
\text { materials from Osteoporosis Canada) }\end{array}$ \\
\hline & $\begin{array}{l}\text { - Knowledge (knowledge from one-on-one } \\
\text { counselling from case manager) }\end{array}$ \\
\hline & $\begin{array}{l}\text { - Beliefs about consequences (beliefs about } \\
\text { consequences of testing and treatment) }\end{array}$ \\
\hline & $\begin{array}{l}\text { - Social influences (case manager as social } \\
\text { influence for patient to agree to BMD scan } \\
\text { and prescription) }\end{array}$ \\
\hline & PCP \\
\hline & $\begin{array}{l}\text { - Memory, attention and decision processes } \\
\text { (attention from patient attending to discuss } \\
\text { the materials) }\end{array}$ \\
\hline & $\begin{array}{l}\text { - Environmental context and resources } \\
\text { (S: BMD scan is a resource) }\end{array}$ \\
\hline & $\begin{array}{l}\text { - Environmental context and resources } \\
\text { (T: prescription for bisphosphonates by study } \\
\text { physician and dispensed by pharmacy is a resource) }\end{array}$ \\
\hline \multirow[t]{9}{*}{ Solomon 2007} & Pharmacists \\
\hline & - Knowledge (knowledge of condition) \\
\hline & - Knowledge (procedural knowledge of academic detailing) \\
\hline & - Skills (skills_practicing physician encounters) \\
\hline & $\begin{array}{l}\text { - Beliefs about capabilities (beliefs about capabilities } \\
\text { targeted using mock scripts) }\end{array}$ \\
\hline & - Goals (reviewed goals of the intervention) \\
\hline & $\begin{array}{l}\text { - Memory, attention and decision processes } \\
\text { (memory/attention-follow-up teleconferences) }\end{array}$ \\
\hline & $\begin{array}{l}\text { - Environmental context and resources } \\
\text { (provision of logistical support is a resource) }\end{array}$ \\
\hline & PCP \\
\hline
\end{tabular}

- Knowledge (educational visit-knowledge of condition)

- Memory, attention and decision processes (decision processes: algorithm for diagnosis and treatment of osteoporosis)

\section{Patient}

- Memory, attention and decision processes (call at 3 months may inadvertently focus patient's attention rather than simply act as an outcome measurement exercise)

Patient

- Knowledge (knowledge from educational materials from Osteoporosis (anada)

- Memory, attention and decision processes (attention: patient asked to discuss materials with PCP)

- Social influences (social influence of study personnel asking patient to discuss materials with the P(P)

PCP

- Memory, attention and decision processes (attention from patient attending to discuss the materials)

None identified 
Table 1 Coding of domains targeted in the intervention and control groups (Continued)

- Environmental context and resources

(double sided laminated card is a resource)

- Environmental context and resources

(tear sheet is a resource)

- Memory, attention and decision processes

(attention from tear sheet)

- Environmental context and resources

(patient list is a resource)

- Memory, attention and decision processes (patient list used during discussion to give examples of patients that should be considered for scan/treatment)

- Social influences (pharmacists as social influence)

- Environmental context and resources

(S: BMD scan offered via automated call is a resource)

Patient

- Memory, attention and decision processes

(S: automated call encouraged members to schedule a BMD scan)

- Knowledge (S: from phone call about osteoporosis and risk information)

- Beliefs about consequences (S: of condition and testing)

- Beliefs about capabilities (S: "only takes 5 min")

- Emotion (S: "painless", "no need to take off clothes")

- Environmental context and resources

(S: resource for scheduling BMD scan)

- Memory, attention and decision processes

(S: second call offering patient opportunity

to schedule BMD scan)

Cranney 2008

PCP

None identified

- Knowledge (from two-page educational tool)

- Beliefs about consequences (of osteoporosis and benefits/risks of treatment)

- Memory, attention and decision processes (attention from letter at 2 weeks post-fracture)

- Memory, attention and decision processes (attention from letter at 2 months post-fracture)

- Memory, attention and decision processes (treatment algorithm aids decision processes)

- Memory, attention and decision processes

(attention from patient attending to discuss osteoporosis)

- Social influences (endorsement from Osteoporosis

Canada acts as social influence)

Patient

- Memory, attention and decision processes (attention from reminder letter at 2 weeks)

- Memory, attention and decision processes (attention from reminder letter at 2 months)

- Beliefs about consequences (future fracture risk)

- Knowledge (from checklist of risks for fractures and 5-year absolute fracture risk)

- Knowledge (from educational booklet about osteoporosis treatment options) 
Table 1 Coding of domains targeted in the intervention and control groups (Continued)

\begin{tabular}{|c|c|}
\hline \multirow[t]{20}{*}{ Majumdar 2008} & Patient \\
\hline & $\begin{array}{l}\text { - Knowledge (of condition from Osteoporosis } \\
\text { Canada pamphlet) }\end{array}$ \\
\hline & - Social influences (of Osteoporosis Canada) \\
\hline & $\begin{array}{l}\text { - Beliefs about consequences (pamphlet } \\
\text { highlighting fractures as harbinger of future events) }\end{array}$ \\
\hline & $\begin{array}{l}\text { - Memory, attention and decision processes } \\
\text { (attention: pamphlet emphasising importance } \\
\text { of follow-up) }\end{array}$ \\
\hline & $\begin{array}{l}\text { - Environmental context and resources } \\
\text { (contact information is a resource) }\end{array}$ \\
\hline & $\begin{array}{l}\text { - Knowledge (from printed materials with } \\
3 \text { key messages) }\end{array}$ \\
\hline & - Knowledge (telephone call reiterated 3 key messages) \\
\hline & $\begin{array}{l}\text { - Beliefs about consequences ( } 3 \text { key messages } \\
\text { addressed beliefs about consequences of } \\
\text { investigation/treatment) }\end{array}$ \\
\hline & - Social influences (of nurse during phone call) \\
\hline & - Beliefs about consequences (nurse allayed concerns) \\
\hline & • Emotions (nurse allayed concerns) \\
\hline & $\begin{array}{l}\text { - Environmental context and resources } \\
\text { (nurse as a resource-answered any questions) }\end{array}$ \\
\hline & PCP \\
\hline & $\begin{array}{l}\text { - Memory, attention and decision processes } \\
\text { (attention from patient attending to } \\
\text { discuss management) }\end{array}$ \\
\hline & $\begin{array}{l}\text { - Memory, attention and decision processes } \\
\text { (attention from patient-specific reminder) }\end{array}$ \\
\hline & $\begin{array}{l}\text { - Beliefs about consequences ( } 3 \text { key messages addressed } \\
\text { beliefs about consequences of investigation/treatment) }\end{array}$ \\
\hline & - Knowledge (from guidelines) \\
\hline & - Social influence (of local opinion leaders) \\
\hline & $\begin{array}{l}\text { - Environmental context and resources } \\
\text { (material resource of printed page with reminder } \\
\text { and treatment guidelines forming part of patient's record }\end{array}$ \\
\hline
\end{tabular}

\section{Patient}

- Knowledge (of condition from Osteoporosis Canada pamphlet)

- Social influences (of Osteoporosis Canada)

- Beliefs about consequences (fractures as harbinger of future events)

- Memory, attention and decision processes (attention from pamphlet emphasising importance of follow-up)

- Environmental context and resources (contact information is a resource)

- Memory, attention and decision processes (attention from second copy of pamphlet)

PCP

- Memory, attention and decision processes (attention from patient attending to discuss pamphlet)

\author{
Patient \\ - Knowledge (from 15-min education) \\ PCP
}

- Memory, attention and decision processes (attention from patient attending for osteoporosis evaluation)
- Memory, attention and decision processes (T: telephone call/clinic visit to assess adherence may target memory to take medication)

- Social influences (T: social influence of orthopaedic surgeon to adhere with treatment)

PCP

- Environmental context and resources (S: evaluation for osteoporosis in hospital including BMD scan is a resource)

- Environmental context and resources (T: follow-up in specialised orthopaedic osteoporosis clinic with commencement of treatment as appropriate is a resource)

- Environmental context and resources (T: telephone call/clinic visit to monitor adherence and assess for complications is a resource) 
Table 1 Coding of domains targeted in the intervention and control groups (Continued)

\begin{tabular}{cc}
\hline Rozental $2008 \quad P C P$ & PCP \\
$\cdot$ & Environmental context and resources (S: BMD scan \\
& ordered by surgeon is a resource) \\
$\cdot$ & Memory, attention and decision processes \\
& (attention from patient following up with PCP) \\
Patient & - Social influences (of orthopaedic surgeon's letter) \\
$\cdot$ & Knowledge (of results of scan) \\
$\cdot$ & Memory, attention and decision processes \\
& (attention: patient encouraged to follow up with PCP) \\
$\cdot$ & Social influences (of NOF guidelines) \\
orthopaedic surgeon to discuss with PCP)
\end{tabular}

Notes: $\mathrm{PCP}=$ primary care physician. A "T" in front of the code indicates that the code is related solely to osteoporosis treatment with anti-resorptive therapy, and $a n$ " $S$ " solely to BMD scanning. The coding specified who the primary recipient of the intervention was, i.e. patient, $\mathrm{PCP}$ or pharmacist

Table 2 presents the number of times each of the domains were coded with respect to BMD scanning and osteoporosis treatment with anti-resorptive therapy in the intervention group of each of the studies. The recipient of the intervention, i.e. patient or PCP, was also specified.

The domain coded most frequently was "memory, attention and decision processes" (10 of 10 interventions; BMD scanning coded 33 times; treatment coded 29 times). The second most frequently coded domain was "knowledge" (10 of 10 interventions; BMD scanning coded 21 times; treatment coded 20 times), closely followed by "environmental context and resources" (9 of 10 interventions; BMD scanning coded 16 times; treatment coded 13 times), "social influences" (9 of 10 interventions; BMD scanning coded 11 times; treatment coded 11 times) and then "beliefs about consequences" (5 of 10 interventions; BMD scanning coded 9 times; treatment coded 9 times). In all of the studies, there was a combination of at least four of these five domains. There were five domains that were never coded: "social/professional role and identity"; "optimism"; "reinforcement"; "intentions"; and "behavioural regulation". The remaining four domains ("skills"; "beliefs about capabilities"; "goals"; "emotion") were coded only once or twice with respect to both BMD scanning and treatment.

Table 3 presents the number of times each of the domains were coded with respect to BMD scanning and osteoporosis treatment with anti-resorptive therapy in the control groups of each of the studies.

We identified and coded domains in the control group for only five of the studies. This was due to the poor descriptions of the care given to the control groups. Fewer elements were coded, and these were spread over fewer domains. The domains most frequently identified in the description of the control group were again "memory, attention and decision processes" (4 of 9 control groups; BMD scanning coded 7 times; treatment coded 7 times), "knowledge" (4 of 9 control groups; BMD scanning coded
4 times; treatment coded 4 times) and "social influences" (3 of 9 control groups; BMD scanning coded 4 times; treatment coded 4 times). "Beliefs about consequences" and "environmental context and resources" were coded once each for both BMD scanning and treatment.

Across the studies described as having been tailored to identified barriers and facilitators, each reported lack of clarity regarding which physician was responsible for the investigation and management of osteoporosis following a fragility fracture as a significant barrier but the interventions themselves were not described to target the "social/professional role and identity" domain for any of these studies. The interventions instead addressed this barrier either by taking the behaviour out of the hands of the PCP altogether ("environmental context and resources") or by using reminders for the PCP to perform the behaviour ("memory, attention and decision processes").

On the whole, the remainder of the barriers and facilitators that were identified in the studies were reflected in the frequency of the domains coded, with the exception of the "social influences" domain. This was the fourth most frequently coded domain and yet was only referred to in one study as being important in changing health care professionals' behaviour [41]. Only one study addressed the "social influences" domain, by selecting local opinion leaders that had been identified as educationally influential physician peers in the area of osteoporosis by PCPs through a validated questionnaire prior to the intervention [43].

\section{Relationship between total number of times the domains are coded within an intervention and effect size}

Table 4 summarises the total number of times the domains were coded, for each study intervention and control group by BMD scanning and osteoporosis treatment with anti-resorptive therapy. Scatterplots are presented in Fig. 1. 
Table 2 Number of times each domain coded in the intervention group

\begin{tabular}{|c|c|c|c|c|c|c|c|c|c|c|c|c|c|c|c|c|c|c|c|c|c|c|}
\hline \multirow[b]{2}{*}{ Domains } & \multirow[b]{2}{*}{ Behaviour } & \multicolumn{2}{|c|}{$\begin{array}{l}\text { Gardner } \\
\text { (2005) }\end{array}$} & \multirow{2}{*}{$\begin{array}{l}\begin{array}{l}\text { Feldstein } 1 \\
(2006)\end{array} \\
P C P\end{array}$} & \multicolumn{2}{|c|}{$\begin{array}{l}\text { Feldstein } 2 \\
\text { (2006) }\end{array}$} & \multicolumn{2}{|c|}{$\begin{array}{l}\text { Davis } \\
(2007)\end{array}$} & \multicolumn{2}{|c|}{$\begin{array}{l}\text { Majumdar } \\
(2007)\end{array}$} & \multicolumn{3}{|c|}{$\begin{array}{l}\text { Solomon } \\
\text { (2007) }\end{array}$} & \multicolumn{2}{|c|}{$\begin{array}{l}\text { Cranney } \\
(2008)\end{array}$} & \multicolumn{2}{|c|}{$\begin{array}{l}\text { Majumdar } \\
\text { (2008) }\end{array}$} & \multicolumn{2}{|c|}{$\begin{array}{l}\text { Miki } \\
(2008)\end{array}$} & \multicolumn{2}{|c|}{$\begin{array}{l}\text { Rozental } \\
\text { (2008) }\end{array}$} & \multirow[t]{2}{*}{ Total } \\
\hline & & Pt. & PCP & & Pt. & PCP & Pt. & PCP & Pt. & PCP & Pt. & PCP & Pharm & Pt. & PCP & Pt. & PCP & Pt. & PCP & Pt. & PCP & \\
\hline \multirow[t]{2}{*}{ 1. Knowledge } & Scan & 1 & & 1 & 1 & 1 & 1 & & 2 & & 1 & 1 & 2 & 2 & 1 & 3 & 1 & 2 & & 1 & & 21 \\
\hline & Treatment & 1 & & 1 & 1 & 1 & 1 & & 2 & & & 1 & 2 & 2 & 1 & 3 & 1 & 2 & & 1 & & 20 \\
\hline \multirow[t]{2}{*}{ 2. Skills } & Scan & & & & & & & & & & & & 1 & & & & & & & & & 1 \\
\hline & Treatment & & & & & & & & & & & & 1 & & & & & & & & & 1 \\
\hline \multirow[t]{2}{*}{ 3. Social/professional role and identity } & Scan & & & & & & & & & & & & & & & & & & & & & 0 \\
\hline & Treatment & & & & & & & & & & & & & & & & & & & & & 0 \\
\hline \multirow[t]{2}{*}{ 4. Beliefs about capabilities } & Scan & & & & & & & & & & 1 & & 1 & & & & & & & & & 2 \\
\hline & Treatment & & & & & & & & & & & & 1 & & & & & & & & & 1 \\
\hline \multirow[t]{2}{*}{ 5. Optimism } & Scan & & & & & & & & & & & & & & & & & & & & & 0 \\
\hline & Treatment & & & & & & & & & & & & & & & & & & & & & 0 \\
\hline \multirow[t]{2}{*}{ 6. Beliefs about consequences } & Scan & 1 & & & & & & & 1 & & 1 & & & 1 & 1 & 3 & 1 & & & & & 9 \\
\hline & Treatment & 2 & & & & & & & 1 & & & & & 1 & 1 & 3 & 1 & & & & & 9 \\
\hline \multirow[t]{2}{*}{ 7. Reinforcement } & Scan & & & & & & & & & & & & & & & & & & & & & \\
\hline & Treatment & & & & & & & & & & & & & & & & & & & & & 0 \\
\hline \multirow[t]{2}{*}{ 8. Intentions } & Scan & & & & & & & & & & & & & & & & & & & & & 0 \\
\hline & Treatment & & & & & & & & & & & & & & & & & & & & & 0 \\
\hline \multirow[t]{2}{*}{ 9. Goals } & Scan & & 1 & & & & & & & & & & 1 & & & & & & & & & 2 \\
\hline & Treatment & & 1 & & & & & & & & & & 1 & & & & & & & & & 2 \\
\hline 10. Memory, attention and decision processes & Scan & 1 & 2 & 2 & 1 & 5 & 2 & 2 & & 1 & 2 & 3 & 1 & 2 & 4 & 1 & 2 & & & 1 & 1 & 33 \\
\hline & Treatment & 1 & 2 & 2 & 1 & 5 & 1 & & & 1 & & 3 & 1 & 2 & 4 & 1 & 2 & 1 & & 1 & 1 & 29 \\
\hline 11. Environmental context and resources & Scan & 1 & & 1 & & 1 & 1 & & & 1 & 1 & 4 & 1 & & & 2 & 1 & & 1 & & 1 & 16 \\
\hline & Treatment & 1 & & 1 & & 1 & & & & 1 & & 3 & 1 & & & 2 & 1 & & 2 & & & 13 \\
\hline 12. Social influences & Scan & & & 1 & 1 & 1 & & 1 & 1 & & & 1 & & & 1 & 2 & 1 & & & 1 & & 11 \\
\hline & Treatment & & & 1 & 1 & 1 & & & 1 & & & 1 & & & 1 & 2 & 1 & 1 & & 1 & & 11 \\
\hline 13. Emotion & Scan & & & & & & & & & & 1 & & & & & 1 & & & & & & 2 \\
\hline & Treatment & & & & & & & & & & & & & & & 1 & & & & & & 1 \\
\hline 14. Behavioural regulation & Scan & & & & & & & & & & & & & & & & & & & & & 0 \\
\hline & Treatment & & & & & & & & & & & & & & & & & & & & & 0 \\
\hline Total no. of domains targeted & Scan & 4 & 3 & 5 & 3 & 8 & 4 & 3 & 4 & 2 & 7 & 9 & 7 & 5 & 7 & 12 & 6 & 2 & 1 & 3 & 2 & \\
\hline & Treatment & 5 & 3 & 5 & 3 & 8 & 2 & & 4 & 2 & & 8 & 7 & 5 & 7 & 12 & 6 & 4 & 2 & 3 & 1 & \\
\hline
\end{tabular}


Table 3 Number of times each domain coded in the control group

\begin{tabular}{|c|c|c|c|c|c|c|c|c|c|c|c|c|c|c|c|c|c|c|c|c|c|}
\hline \multirow[b]{2}{*}{ Domains } & \multirow[b]{2}{*}{ Behaviour } & \multicolumn{2}{|c|}{$\begin{array}{l}\text { Gardner } \\
(2005)\end{array}$} & \multicolumn{2}{|c|}{$\begin{array}{l}\text { Feldstein } \\
\text { (2006) }\end{array}$} & \multicolumn{2}{|c|}{$\begin{array}{l}\text { Davis } \\
\text { (2007) }\end{array}$} & \multicolumn{2}{|c|}{$\begin{array}{l}\text { Majumdar } \\
(2007)\end{array}$} & \multicolumn{3}{|c|}{$\begin{array}{l}\text { Solomon } \\
\text { (2007) }\end{array}$} & \multicolumn{2}{|c|}{$\begin{array}{l}\text { Cranney } \\
(2008)\end{array}$} & \multicolumn{2}{|c|}{$\begin{array}{l}\text { Majumdar } \\
\text { (2008) }\end{array}$} & \multicolumn{2}{|c|}{$\begin{array}{l}\text { Miki } \\
(2008)\end{array}$} & \multicolumn{2}{|c|}{$\begin{array}{l}\text { Rozental } \\
\text { (2008) }\end{array}$} & \multirow[t]{2}{*}{ Total } \\
\hline & & Pt. & $\overline{P C P}$ & Pt. & $\overline{P C P}$ & $\mathrm{Pt}$. & $\overline{P C P}$ & Pt. & $P C P$ & $\overline{\mathrm{Pt}}$ & $\mathrm{PCP}$ & Pharm & Pt. & $\overline{P C P}$ & Pt. & $\mathrm{PCP}$ & Pt. & $\mathrm{PCP}$ & Pt. & $\overline{P C P}$ & \\
\hline \multirow[t]{2}{*}{ 1. Knowledge } & Scan & & & & & & & 1 & & & & & & & 1 & & 1 & & & 1 & 4 \\
\hline & Treatment & & & & & & & 1 & & & & & & & 1 & & 1 & & & 1 & 4 \\
\hline \multirow[t]{2}{*}{ 2. Skills } & Scan & & & & & & & & & & & & & & & & & & & & \\
\hline & Treatment & & & & & & & & & & & & & & & & & & & & \\
\hline \multirow[t]{2}{*}{ 3. Social/ professional role and identity } & Scan & & & & & & & & & & & & & & & & & & & & \\
\hline & Treatment & & & & & & & & & & & & & & & & & & & & \\
\hline \multirow[t]{2}{*}{ 4. Beliefs about capabilities } & Scan & & & & & & & & & & & & & & & & & & & & \\
\hline & Treatment & & & & & & & & & & & & & & & & & & & & \\
\hline \multirow[t]{2}{*}{ 5. Optimism } & Scan & & & & & & & & & & & & & & & & & & & & \\
\hline & Treatment & & & & & & & & & & & & & & & & & & & & \\
\hline \multirow[t]{2}{*}{ 6. Beliefs about consequences } & Scan & & & & & & & & & & & & & & 1 & & & & & & 1 \\
\hline & Treatment & & & & & & & & & & & & & & 1 & & & & & & 1 \\
\hline \multirow[t]{2}{*}{ 7. Reinforcement } & Scan & & & & & & & & & & & & & & & & & & & & \\
\hline & Treatment & & & & & & & & & & & & & & & & & & & & \\
\hline \multirow[t]{2}{*}{ 8. Intentions } & Scan & & & & & & & & & & & & & & & & & & & & \\
\hline & Treatment & & & & & & & & & & & & & & & & & & & & \\
\hline \multirow[t]{2}{*}{ 9. Goals } & Scan & & & & & & & & & & & & & & & & & & & & \\
\hline & Treatment & & & & & & & & & & & & & & & & & & & & \\
\hline \multirow[t]{2}{*}{ 10. Memory, attention and decision processes } & Scan & & & & & 1 & & 1 & 1 & & & & & & 2 & 1 & & 1 & & & 7 \\
\hline & Treatment & & & & & 1 & & 1 & 1 & & & & & & 2 & 1 & & 1 & & & 7 \\
\hline 11. Environmental context and resources & Scan & & & & & & & & & & & & & & 1 & & & & & & 1 \\
\hline & Treatment & & & & & & & & & & & & & & 1 & & & & & & 1 \\
\hline 12. Social influences & Scan & & & & & & & 1 & & & & & & & 1 & & & & & 2 & 4 \\
\hline & Treatment & & & & & & & 1 & & & & & & & 1 & & & & & 2 & 4 \\
\hline 13. Emotion & Scan & & & & & & & & & & & & & & & & & & & & \\
\hline & Treatment & & & & & & & & & & & & & & & & & & & & \\
\hline 14. Behavioural regulation & Scan & & & & & & & & & & & & & & & & & & & & \\
\hline & Treatment & & & & & & & & & & & & & & & & & & & & \\
\hline Total no. of domains targeted & Scan & 0 & 0 & 0 & 0 & 1 & 0 & 3 & 1 & 0 & 0 & 0 & 0 & 0 & 6 & 1 & 1 & 1 & 0 & 3 & \\
\hline & Treatment & 0 & 0 & 0 & 0 & 1 & 0 & 3 & 1 & 0 & 0 & 0 & 0 & 0 & 6 & 1 & 1 & 1 & 0 & 3 & \\
\hline
\end{tabular}


Table 4 Total number of times domains coded within intervention and control groups

\begin{tabular}{|c|c|c|c|c|c|c|c|c|}
\hline \multirow[t]{2}{*}{ Studies } & \multicolumn{2}{|c|}{$\begin{array}{l}\text { Total no. times any domain } \\
\text { coded Intervention }\end{array}$} & \multicolumn{2}{|c|}{$\begin{array}{l}\text { Total no. times any domain } \\
\text { coded control }\end{array}$} & \multicolumn{2}{|c|}{ Intervention minus control } & \multicolumn{2}{|c|}{$\begin{array}{l}\text { Post-intervention } \\
\text { risk difference (\%) }\end{array}$} \\
\hline & Scanning & Treatment & Scanning & Treatment & Scanning & Treatment & Scanning & Treatment \\
\hline Gardner 2005 & 7 & 8 & 0 & 0 & 7 & 8 & 17 & 11 \\
\hline \multicolumn{9}{|l|}{ Feldstein 2006} \\
\hline Intervention 1 & 5 & 5 & 0 & 0 & 5 & 5 & 38 & 23 \\
\hline Intervention 2 & 11 & 11 & & & 11 & 11 & 31 & 15 \\
\hline Davis 2007 & 7 & 2 & 1 & 1 & 6 & 1 & 29 & 54 \\
\hline Majumdar 2007 & 6 & 6 & 4 & 4 & 2 & 2 & 51 & 29 \\
\hline Solomon 2007 & 23 & 15 & 0 & 0 & 23 & 15 & 4 & 3 \\
\hline Cranney 2008 & 12 & 12 & 0 & 0 & 12 & 12 & 28 & 18 \\
\hline Majumdar 2008 & 18 & 18 & 7 & 7 & 11 & 11 & 34 & 14 \\
\hline Miki 2008 & 3 & 6 & 2 & 2 & 1 & 4 & 71 & 29 \\
\hline Rozental 2008 & 5 & 4 & 3 & 3 & 2 & 1 & 62 & 8 \\
\hline
\end{tabular}

There was a statistically significant inverse relationship between the total number of times the domains were coded within an intervention and the post-intervention risk difference for BMD scanning, $r=-0.831, p<0.05$ but not for treatment $(r=-0.615, p=0.058)$. The sensitivity analysis (not subtracting the number of control group domains) showed similar results (BMD scanning: $r=-0.704$, $p<0.05$; treatment: $r=-0.603, p=0.065)$.

\section{Relationship between the number of different domains coded within an intervention and the effect size}

Table 5 summarises the number of different domains coded in the intervention and control groups of each of the studies. Scatterplots are presented in Fig. 2.

There was a statistically significant inverse relationship between number of different domains coded within an intervention and the post-intervention risk difference for BMD scanning $(r=-0.848, p<0.05)$ but not for treatment $(r=-0.530, p=0.115)$. The sensitivity analysis (no subtraction of control group domains) showed similar results for BMD scanning $(r=-0.728, p<0.05)$, but for treatment, the relationship became statistically significant $(r=-0.644, p<0.05)$.

\section{Discussion}

We conducted a theory-based analysis of the interventions from nine randomised controlled trials (RCTs) included in a systematic review to assess the effectiveness of a variety of interventions to improve the investigation and management of osteoporosis following fragility fracture. Although there are many examples of the prospective use of the TDF in implementation research, to our knowledge, this is the first time that the TDF has been used as a coding framework to retrospectively analyse the factors targeted by implementation interventions in a systematic review.

The theory-based analysis using the TDF highlighted five key domains that appeared to be targeted most frequently by the interventions: "Memory, attention and decision processes", "knowledge", "environmental context and resources", "social influences" and "beliefs about consequences". For each of the ten interventions from the nine studies, we coded a combination of at least four of these five domains. The results of the exploratory quantitative analysis suggested an inverse relationship between both the number of times the domains were coded and the number of different domains coded and the effect size of the intervention for BMD scanning, but the relationship was less clear with regards to treatment with anti-resorptive therapy.

\section{Frequently coded domains}

"Memory, attention and decision processes" was by far the most frequently coded domain. This suggests that the study authors believed that PCPs need reminders, prompts or decision aids to enable them to perform the behaviours, indicating that they believed that PCPs were either forgetting to perform the behaviour or had impaired decision processes with regard to performing the behaviour. This also addressed the identified barrier of PCPs failing to make the connection between a fracture and osteoporosis.

"Knowledge" was the second most frequently coded domain. For all the interventions that included the patient as a recipient, the "knowledge" domain was coded with respect to the patient. This indicates that the authors believed that in order to ensure that the patient could influence the PCP's behaviour, they first required a certain amount of knowledge about the investigation 
Bone mineral density scanning

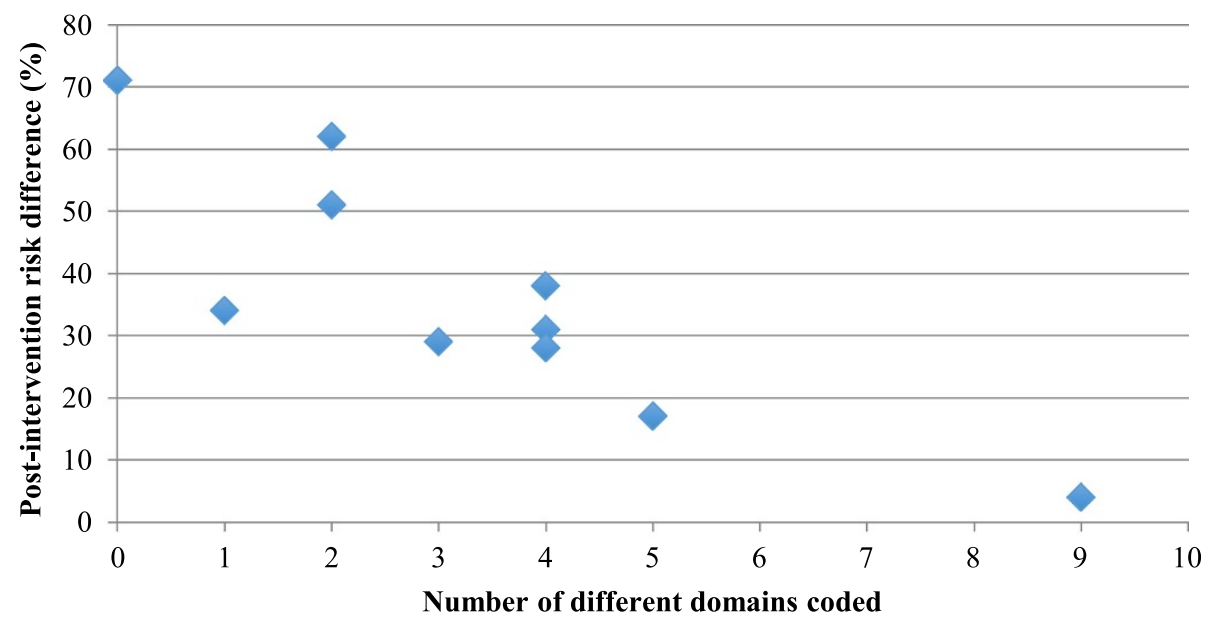

Treatment with anti-resorptive therapy

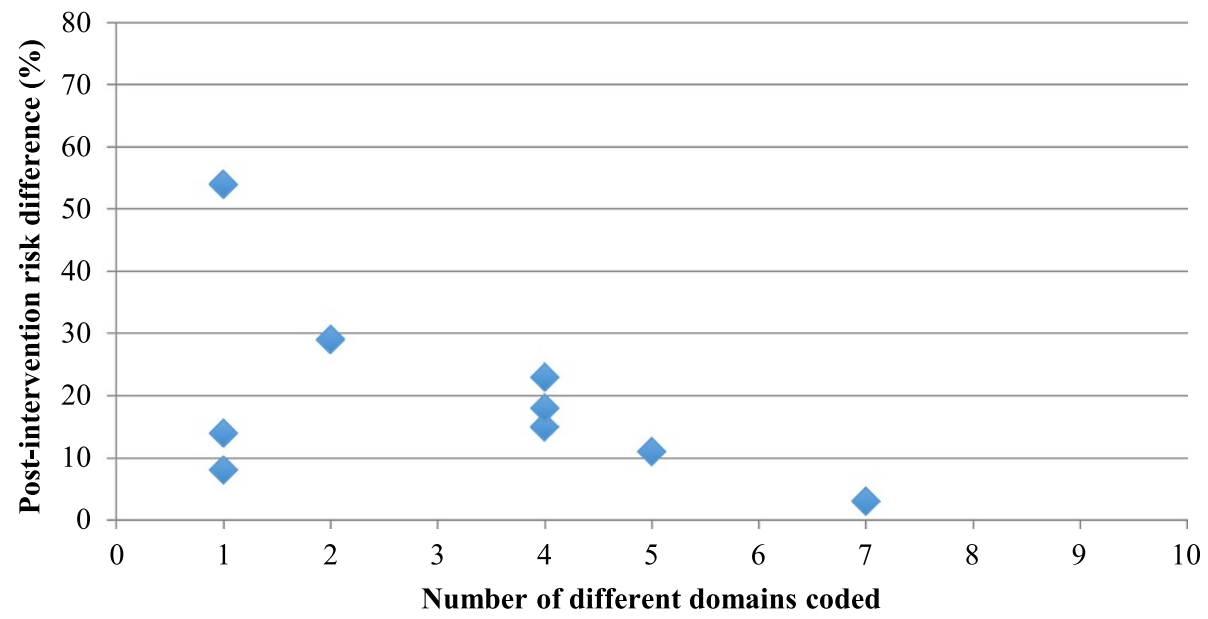

Fig. 1 Scatterplot of total number of times the domains were coded and intervention effect size (BMD scanning and treatment with anti-resorptive therapy)

and management of osteoporosis following fragility fracture. The use of "knowledge" with regards to the PCP was less consistent (five out of ten interventions) which suggests that the study authors differed in their views about PCPs' existing knowledge of the condition and its management. This domain encompasses the barriers of a lack of awareness by patients and physicians of the treatment guidelines and efficacy of medications for osteoporosis following fragility fracture.

"Environmental context and resources" was the third most frequently coded domain. It was interesting that in the three studies with the greatest effect sizes for BMD scanning (Miki [44], Rozental [45] and Majumdar [40], with post-intervention risk differences of 71,62 and $51 \%$, respectively), a large part of the intervention was coded within this domain. In the Miki study, the BMD scan was ordered by the orthopaedic surgeon and carried out whilst the patient was still in hospital. In Rozental the BMD scan was ordered by the orthopaedic surgeon during the first outpatient clinic visit; and in Majumdar, a case manager arranged the BMD scan. This was coded as a resource, but one could argue that rather than changing the behaviour of the PCP, the effectiveness of the interventions stemmed from the fact that the behaviour was taken completely out of the hands of the PCP and was actually a service delivery change-someone else performed the behaviour instead. In these three examples, the barrier of inadequate access to BMD scanning was addressed. It is worth noting that this domain was also coded for studies with smaller effect sizes for BMD scanning, including Solomon which had the smallest effect size (4\%) [41], and in which it was coded once for the patient, four times for 
Table 5 Number of different domains coded within intervention and control groups and intervention effect size

\begin{tabular}{|c|c|c|c|c|c|c|c|c|}
\hline \multirow[t]{2}{*}{ Studies } & \multicolumn{2}{|c|}{$\begin{array}{l}\text { Number of different domains } \\
\text { coded Intervention }\end{array}$} & \multicolumn{2}{|c|}{$\begin{array}{l}\text { Number of different domains } \\
\text { coded control }\end{array}$} & \multicolumn{2}{|c|}{ Intervention minus control } & \multicolumn{2}{|c|}{$\begin{array}{l}\text { Post-intervention risk } \\
\text { difference (\%) }\end{array}$} \\
\hline & Scanning & Treatment & Scanning & Treatment & Scanning & Treatment & Scanning & Treatment \\
\hline Gardner 2005 & 5 & 5 & 0 & 0 & 5 & 5 & 17 & 11 \\
\hline \multicolumn{9}{|l|}{ Feldstein 2006} \\
\hline Intervention 1 & 4 & 4 & 0 & 0 & 4 & 4 & 38 & 23 \\
\hline Intervention 2 & 4 & 4 & & & 4 & 4 & 31 & 15 \\
\hline Davis 2007 & 4 & 2 & 1 & 1 & 3 & 1 & 29 & 54 \\
\hline Majumdar 2007 & 5 & 5 & 3 & 3 & 2 & 2 & 51 & 29 \\
\hline Solomon 2007 & 9 & 7 & 0 & 0 & 9 & 7 & 4 & 3 \\
\hline Cranney 2008 & 4 & 4 & 0 & 0 & 4 & 4 & 28 & 18 \\
\hline Majumdar 2008 & 6 & 6 & 5 & 5 & 1 & 1 & 34 & 14 \\
\hline Miki 2008 & 2 & 4 & 2 & 2 & 0 & 2 & 71 & 29 \\
\hline Rozental 2008 & 4 & 3 & 2 & 2 & 2 & 1 & 62 & 8 \\
\hline
\end{tabular}

\section{Bone mineral density scanning}

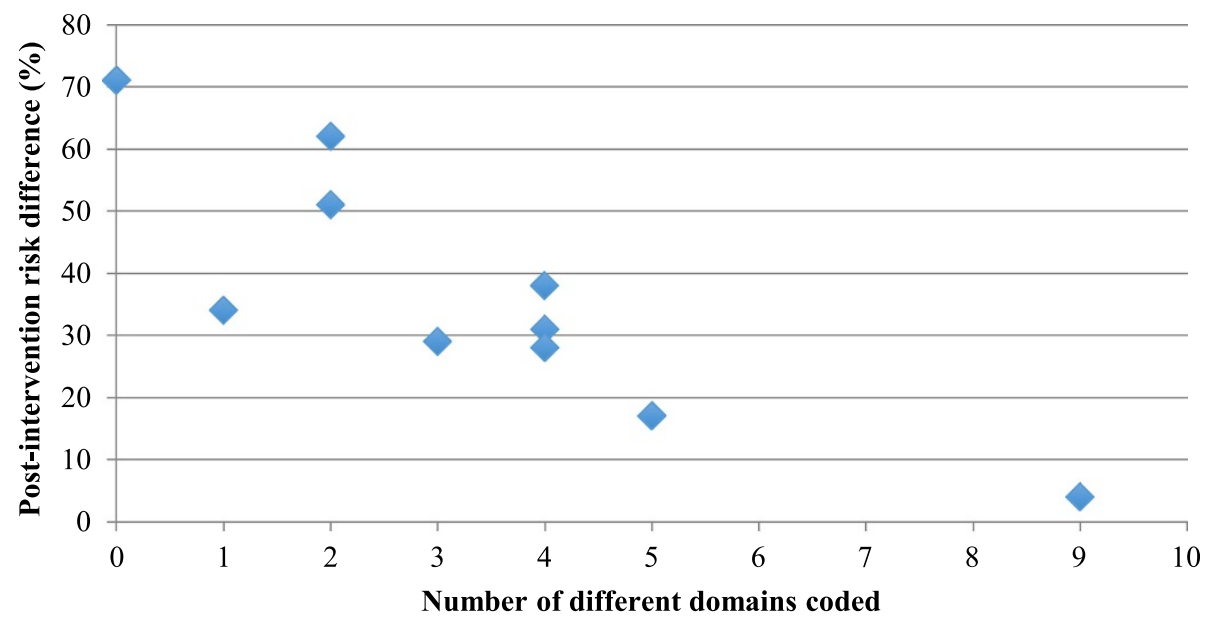

Treatment with anti-resorptive therapy

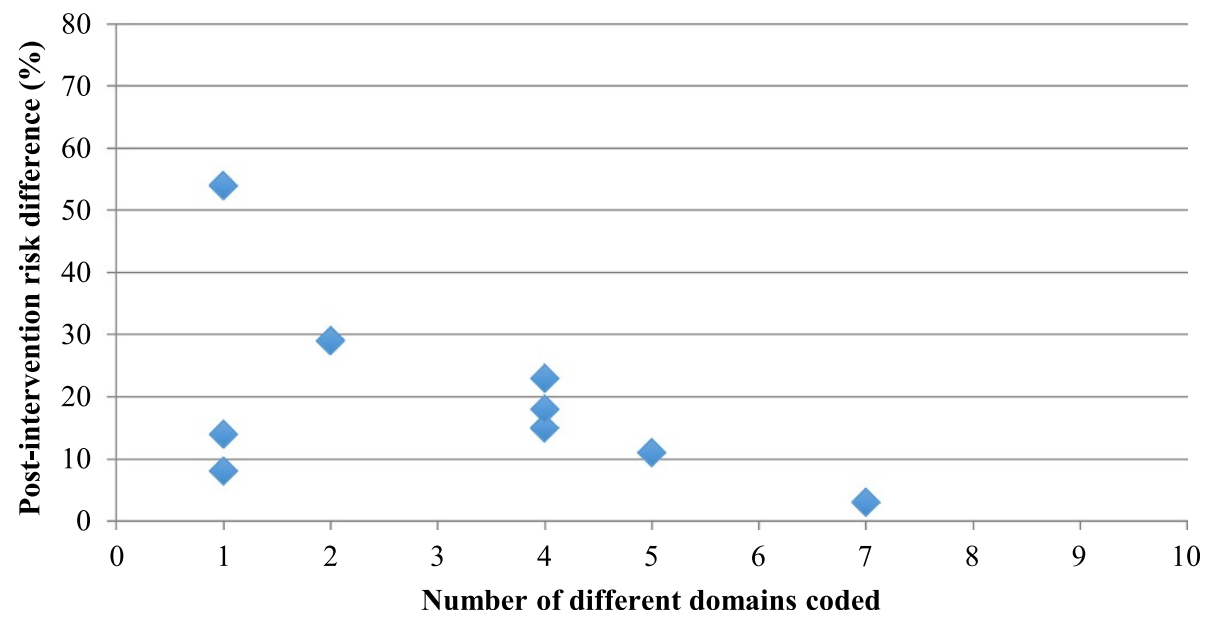

Fig. 2 Scatterplot of number of different domains coded and intervention effect size (BMD scanning and treatment with anti-resorptive therapy) 
the PCP and once for the pharmacist. This highlights a key point when using the TDF: it is not just which domains you target but how they are targeted that is important. Just because one targets "environmental context and resources" or "Memory, attention and decision processes,' it does not mean that it is done appropriately or effectively. However, the advantage of using the TDF is that it allows us to use a common language for describing those targets.

Finally, "Beliefs about consequences" was coded fifth most frequently. Interestingly, patient "beliefs about consequences" was targeted in all of the five studies for which this domain was coded but PCP "beliefs about consequences" was only targeted in two of them. This implies that the authors believed that patients had not considered or did not understand the consequences of failing to investigate for and treat osteoporosis post-fracture, and by remedying this, they would be able to change the behaviour of the PCP by, for example, using patient prompts. This addressed barriers such as concerns about whether bisphosphonate treatment might impair fracture-healing, concerns about adverse effects of medications or lack of awareness of the efficacy of medications following fracture.

\section{Description of intervention and control groups}

In addition to the poor reporting of the rationale for the interventions, from some of the descriptions given, it was difficult to extract sufficient detail to be confident that the interventions were being described in a way that would make them replicable. It was also difficult to disentangle what the investigators felt was the content of their intervention (the active ingredients; cf. [47]) from the method that they chose to deliver it (e.g. printed educational materials). Such distinction is important in order to promote greater clarity in the description of interventions [48].

The descriptions of the control groups were often underreported, and in some cases completely absent. This impacted on our ability to code certain domains with confidence. This is a consistent finding throughout the behaviour change literature. Reviews of nearly 1000 behaviour change outcome studies [49-52] found that detailed descriptions of interventions were present in only 5 to $30 \%$. Failing to report the actual behaviour targeted for change by the intervention or describing the content of the intervention in sufficient detail makes it impossible to identify why an intervention did or did not work $[53,54]$. This prevents the replication of successful interventions in wider settings; the introduction of the Template for Intervention Description and Replication checklist (TIDieR) [55] may improve the current situation.

\section{Relationship between the number of domains targeted and the effect size}

The exploratory analysis showed a statistically significant inverse relationship between the total number of times the domains were coded and the number of different domains coded and the effect size of the intervention for BMD scanning. However, the results for the equivalent analysis on anti-resorptive therapy were not statistically significant. This may be due to the fact that antiresorptive therapy is itself partially dependent upon BMD scanning. We have shown that the study authors rarely documented the management guideline they were using, but in the majority of cases, the patient needed to have a BMD scan before treatment was commenced. Following the BMD scan, the patient may not have required treatment for osteoporosis so although the patient would have received appropriate care, it would appear as if the intervention had not been successful as the patient was not given subsequent anti-resorptive treatment.

Nevertheless, the inverse relationship demonstrated for BMD scanning was unexpected. We assumed that multifaceted interventions would prove to be associated with larger effect sizes. There may be a range of reasons that explain the inverse relationship, including that it is a chance finding given the small number of studies included in the analysis. Equally, it may be that targeting more domains may not be inherently better; what is likely more important may be to better match the interventions to the domains shown to be relevant for the behaviour, context and population under study [16].

\section{Limitations and challenges}

None of the studies employed the explicit use of theory, which meant that our coding was based on inference from the text. This is not unusual; studies in this area rarely employ theories of behaviour change, or if they do, they fail to report it [56].

The main limitation with the exploratory quantitative analysis of the relationship between domains coded and effect size of the intervention was that there were only 10 data points; outliers had a large influence on the results. Although there was only moderate agreement achieved ( $K=0.507)$ following the initial coding, the multidisciplinary coding approach likely allowed for better sensitivity of both the clinical and theoretical content.

There are also challenges to using the TDF itself in this context. Not all domains are necessarily mutually exclusive, with some sharing certain constructs, for example, "action planning" is a part of both "goals" and "behavioural regulation". Separating "intentions" and "goals" domains was sometimes a challenge. Given the inferential nature of the coding, there were instances when agreeing upon a target domain proved challenging (reflected in our inter-rater 
reliability). This was in line with previous research in the context of interview studies [57], perhaps reflecting the difficulty of clarifying the boundaries between some domains when using the TDF as a coding framework.

A final challenge involved coding interventions that included a service delivery change. In three studies, the behaviour of performing the BMD scan was taken out of the hands of the target $\mathrm{PCP}$ altogether and performed by another individual. We coded such instances as targeting "environmental context and resources" domain. However, the target of this part of the intervention was at an organisational level rather than an individual PCP or patient level. Nevertheless, someone's behaviour higher in the organisation needed to change for this service delivery to take effect; the TDF could potentially be applied to describe their behaviour as well in future studies if descriptions in intervention reports provide such detail.

\section{Conclusion}

It is possible to use the TDF to retrospectively identify domains targeted by implementation interventions within systematic reviews. Even when the interventions themselves were not explicitly theory-based, the findings suggest that it is possible to attempt to make explicit the implicit theories that formed the basis for intervention. We identified five key domains that appeared to be most frequently targeted by the interventions. Interventions could be optimised by assessing whether these domains appear to be determinants of the target behaviour. We also identified a number of domains that had not been targeted, which could be considered as targets in future interventions if indicated to be barriers or facilitators. Unexpectedly, the results suggested that the effect size was inversely related to the number of domains targeted by an intervention, with the potential implication that focussing on less domains makes interventions more effective. The method proposed may serve as a basis for using the TDF as a means of better understanding the targeted factors in reviews of implementation interventions in other contexts when such factors are not explicitly identified within an existing theoretical framework.

\section{Additional files}

Additional file 1: Data extraction form for theory-based analysis.

Additional file 2: Detailed coding of domains targeted in the intervention and control groups.

\section{Competing interests}

MPE is the founding Editor-in-Chief of Implementation Science. JP is an editorial board member of Implementation Science. Neither was involved in the editorial decisions for this manuscript.

\section{Authors' contributions}

MPE conceived of the study. EAL and JP coded the intervention and control groups: EAL conducted the quantitative analysis under JP's supervision. EAL wrote the first draft of the manuscript, and all authors commented on it and the subsequent drafts. All authors read and approved the final manuscript.

Received: 28 January 2015 Accepted: 8 June 2015

Published online: 17 June 2015

\section{References}

1. Albarracin D, Gillette JC, Earl AN, Glasman LR, Durantini MR, Ho MH. A test of major assumptions about behavior change: a comprehensive look at the effects of passive and active HIV-prevention interventions since the beginning of the epidemic. Psychol Bull. 2005;131(6):856-97.

2. Noar SM, Zimmerman RS. Health Behavior Theory and cumulative knowledge regarding health behaviors: are we moving in the right direction? Health Educ Res. 2005;20(3):275-90.

3. Presseau J, Johnston M, Heponiemi T, Elovainio M, Francis JJ, Eccles MP, et al. Reflective and automatic processes in healthcare professional behavior: a dual process model tested across multiple behaviors. Ann Behav Med. 2014;48:347-58.

4. Presseau J, Johnston M, Francis JJ, Hrisos S, Stamp E, Steen N, et al. Theory-based predictors of multiple clinician behaviors in the management of diabetes. J Behav Med. 2014:37:607-20.

5. Walker AE, Grimshaw J, Johnston M, Pitts N, Steen N, Eccles M. PRIME-PRocess modelling in ImpleMEntation research: selecting a theoretical basis for interventions to change clinical practice. BMC Health Serv Res. 2003;19(3(1)):22.

6. Michie $S$, Abraham C. Identifying techniques that promote health behaviour change: evidence based or evidence inspired? Psychol Health. 2004;19:29-49.

7. Presseau J, Hawthorne G, Sniehotta FF, Steen N, Francis JJ, Johnston M, et al. Improving diabetes care through examining, advising, and prescribing (IDEA): protocol for a theory-based cluster randomised controlled trial of a multiple behaviour change intervention aimed at primary healthcare professionals. Implement Sci. 2014;9:61.

8. The Improved Clinical Effectiveness through Behavioural Research Group (ICEBeRG). Designing theoretically-informed implementation interventions. Implement Sci. 2006;1:4.

9. Kim N, Stanton B, Li X, Dickersin K, Galbraith J. Effectiveness of the 40 adolescent AIDS-risk reduction interventions: a quantitative review. J Adolesc Health. 1997;20(3):204-15.

10. Eccles M, Grimshaw J, Walker A, Johnston M, Pitts N. Changing the behavior of healthcare professionals: the use of theory in promoting the uptake of research findings. J Clin Epidemiol. 2005;58(2):107-12.

11. Green LW, Glasgow RE. Evaluating the relevance, generalization, and applicability of research: issues in external validation and translation methodology. Eval Health Prof. 2006;29(1):126-53.

12. Foy R, Eccles MP, Jamtvedt G, Young J, Grimshaw JM, Baker R. What do we know about how to do audit and feedback? Pitfalls in applying evidence from a systematic review. BMC Health Serv Res. 2005;5:50.

13. Michie S, Johnston M, Abraham C, Lawton R, Parker D, Walker A. Making psychological theory useful for implementing evidence based practice: a consensus approach. Qual Saf Health Care. 2005;14:26-33.

14. Cane J, O'Connor D, Michie S. Validation of the theoretical domains framework for use in behaviour change and implementation research. Implement Sci. 2012;7:37.

15. Francis JJ, O'Connor D, Curran J. Theories of behaviour change synthesised into a set of theoretical groupings: introducing a thematic series on the theoretical domains framework. Implement Sci. 2012;7:35.

16. French SD, Green SE, O'Connor D, McKenzie JE, Francis J, Michie S, et al. Developing theory-informed behaviour change interventions to implement evidence into practice: a systematic approach using the Theoretical Domains Framework. Implement Sci. 2012;7:38.

17. McSherry LA, Dombrowski SU, Francis JJ, Murphy J, Martin CM, O'Leary JJ, et al. 'It's a can of worms': understanding primary care practitioners' behaviours in relation to HPV using the Theoretical Domains Framework. Implement Sci. 2012;7:73.

18. Duncan EM, Francis JJ, Johnston M, Davey P, Maxwell S, McKay GA, et al Learning curves, taking instructions, and patient safety: using a theoretical domains framework in an interview study to investigate prescribing errors among trainee doctors. Implement Sci. 2012;7:86. 
19. Curran JA, Brehaut J, Patey AM, Osmond M, Stiell I, Grimshaw JM. Understanding the Canadian adult $C T$ head rule trial: use of the theoretical domains framework for process evaluation. Implement Sci. 2013;8:25.

20. Amemori M, Michie S, Korhonen T, Murtomaa H, Kinnunen TH. Assessing implementation difficulties in tobacco use prevention and cessation counselling among dental providers. Implement Sci. 2011;6:50.

21. Giangregorio L, Papaioannou A, Cranney A, Zytaruk N, Adachi JD. Fragility fractures and the osteoporosis care gap: an international phenomenon. Semin Arthritis Rheum. 2006;35(5):293-305.

22. Elliot-Gibson $\mathrm{V}$, Bogoch ER, Jamal SA, Beaton DE. Practice patterns in the diagnosis and treatment of osteoporosis after a fragility fracture: a systematic review. Osteoporos Int. 2004;15(10):767-78.

23. Freedman KB, Kaplan FS, Bilker WB, Strom BL, Lowe RA. Treatment of osteoporosis: are physicians missing an opportunity? J Bone Joint Surg Am. 2000;82-A(8):1063-70.

24. Kamel HK, Hussain MS, Tariq S, Perry HM, Morley JE. Failure to diagnose and treat osteoporosis in elderly patients hospitalized with hip fracture. Am J Med. 2000;109(4):326-8.

25. Colon-Emeric C, Yballe L, Sloane R, Pieper CF, Lyles KW. Expert physician recommendations and current practice patterns for evaluating and treating men with osteoporotic hip fracture. J Am Geriatr Soc. 2000;48(10):1261-3.

26. Gehlbach SH, Bigelow C, Heimisdottir M, May S, Walker M, Kirkwood JR. Recognition of vertebral fracture in a clinical setting. Osteoporos Int 2000;11(7):577-82.

27. Andrade SE, Majumdar SR, Chan KA, Buist DS, Go AS, Goodman M, et al. Low frequency of treatment of osteoporosis among postmenopausal women following a fracture. Arch Intern Med. 2003:22(163(17)):2052-7.

28. Feldstein A, Elmer PJ, Orwoll E, Herson M, Hillier T. Bone mineral density measurement and treatment for osteoporosis in older individuals with fractures: a gap in evidence-based practice guideline implementation. Arch Intern Med. 2003;13(163(18)):2165-72

29. Siris ES, Bilezikian JP, Rubin MR, Black DM, Bockman RS, Bone HG, et al. Pins and plaster aren't enough: a call for the evaluation and treatment of patients with osteoporotic fractures. J Clin Endocrinol Metab. 2003;88(8):3482-6.

30. Torgerson DJ, Dolan P. Prescribing by general practitioners after an osteoporotic fracture. Ann Rheum Dis. 1998;57(6):378-9.

31. Cosman F, Beur SJ, LeBoff MS, Lewiecki EM, Tanner B, Randall S, et al. Clinician's Guide to Prevention and Treatment of Osteoporosis. Osteoporos Int. 2014;25(10):2359-81.

32. Brown JP, Josse RG, Scientific Advisory Council of the Osteoporosis Society of Canada. 2002 clinical practice guidelines for the diagnosis and management of osteoporosis in Canada. CMAJ. 2002;12(167(10 Suppl)):S1-34.

33. Scottish Intercollegiate Guidelines Network: management of osteoporosis. Edinburgh; 2003.

34. National Osteoporosis Guideline Group (NOGG): Guideline for the diagnosis and management of osteoporosis in postmenopausal women and men from the age of 50 years in the UK. Executive Summary; 2008, updated 2010

35. NICE. Alendronate, etidronate, risedronate, raloxifene, strontium ranelate and teriparatide for the secondary prevention of osteoporotic fragility fractures in postmenopausal women. 2008

36. Little EA, Eccles MP. A systematic review of the effectiveness of interventions to improve post-fracture investigation and management of patients at risk of osteoporosis. Implement Sci. 2010;5:80.

37. Gardner MJ, Brophy RH, Demetrakopoulos D, Koob J, Hong R, Rana A, et al Interventions to improve osteoporosis treatment following hip fracture. A prospective, randomized trial. J Bone Joint Surg Am. 2005;87(1):3-7.

38. Feldstein A, Elmer PJ, Smith DH, Herson M, Orwoll E, Chen C, et al. Electronic medical record reminder improves osteoporosis management after a fracture: a randomized, controlled trial. J Am Geriatr Soc. 2006;54(3):450-7

39. Davis JC, Guy P, Ashe MC, Liu-Ambrose T, Khan K. HipWatch: osteoporosis investigation and treatment after a hip fracture: a 6-month randomized controlled trial. J Gerontol A Biol Sci Med Sci. 2007;62(8):888-91.

40. Majumdar SR, Beaupre LA, Harley CH, Hanley DA, Lier DA, Juby AG, et al. Use of a case manager to improve osteoporosis treatment after hip fracture: results of a randomized controlled trial. Arch Intern Med. 2007;22(167(19)):2110-5.

41. Solomon DH, Polinski JM, Stedman M, Truppo C, Breiner L, Egan C, et al. Improving care of patients at-risk for osteoporosis: a randomized controlled trial. J Gen Intern Med. 2007;22(3):362-7.
42. Cranney A, Lam M, Ruhland L, Brison R, Godwin M, Harrison MM, et al. A multifaceted intervention to improve treatment of osteoporosis in postmenopausal women with wrist fractures: a cluster randomized trial. Osteoporos Int. 2008;19(12):1733-40.

43. Majumdar SR, Johnson JA, McAlister FA, Bellerose D, Russell AS, Hanley DA, et al. Multifaceted intervention to improve diagnosis and treatment of osteoporosis in patients with recent wrist fracture: a randomized controlled trial. CMAJ. 2008;26(178(5)):569-75.

44. Miki RA, Oetgen ME, Kirk J, Insogna KL, Lindskog DM. Orthopaedic management improves the rate of early osteoporosis treatment after hip fracture. A randomized clinical trial. J Bone Joint Surg Am. 2008;90(11):2346-53.

45. Rozental TD, Makhni EC, Day CS, Bouxsein ML. Improving evaluation and treatment for osteoporosis following distal radial fractures. A prospective randomized intervention. J Bone Joint Surg Am. 2008;90(5):953-61.

46. Landis JR, Koch GG. The measurement of observer agreement for categorical data. Biometrics. 1977;33(1):159-74.

47. Presseau J, Ivers NM, Newham JJ, Knittle K, Danko KJ, Grimshaw JM. Using a behaviour change techniques taxonomy to identify active ingredients within trials of implementation interventions for diabetes care. Implement Sci. 2015;10:55

48. Michie S, Fixsen D, Grimshaw JM, Eccles MP. Specifying and reporting complex behaviour change interventions: the need for a scientific method. Implement Sci. 2009;4:40

49. Dane AV, Schneider BH. Program integrity in primary and early secondary prevention: are implementation effects out of control? Clin Psychol Rev. 1998;18(1):23-45.

50. Gresham FM, Gansle KA, Noell GH. Treatment integrity in applied behavior analysis with children. J Appl Behav Anal. 1993;26(2):257-63.

51. Moncher FJ, Prinz RJ. Treatment fidelity in outcome studies. Clin Psychol Rev. 1991:11.

52. Odom SI, Brown WH, Frey T, Karasu N, Smith-Canter LL, Strain PS. Evidencebased practices for young children with autism: contributions for singlesubject design research. Focus on Autism and Other Developmental Disabilities. 2003;18:166-75

53. Dombrowski S, Sniehotta F, Avenell A, Coyne J. Towards a cumulative science of behavior change: do current conduct and reporting of behavioral interventions fall short of best practice? Psychol Health 2007;22:869-74.

54. Riley B, MacDonald J, Mansi O, Kothan A, Kurtz D, von Tettenborn L, et al. Is reporting on interventions a weak link in understanding how and why they work? A preliminary exploration using community heart health exemplars. Implement Sci. 2008;3:27.

55. Hoffmann TC, Glasziou PP, Boutron I, Milne R, Perera R, Moher D, et al. Better reporting of interventions: template for intervention description and replication (TIDieR) checklist and guide. BMJ. 2014;7(348):g1687.

56. Davies P, Walker AE, Grimshaw JM. A systematic review of the use of theory in the design of guideline dissemination and implementation strategies and interpretation of the results of rigorous evaluations. Implement Sci. 2010:5:14.

57. Francis JJ, Stockton C, Eccles MP, Johnston M, Cuthbertson BH, Grimshaw $J M$, et al. Evidence-based selection of theories for designing behaviour change interventions: using methods based on theoretical construct domains to understand clinicians' blood transfusion behaviour. Br J Health Psychol. 2009;14(Pt 4):625-46.

\section{Submit your next manuscript to BioMed Central and take full advantage of:}

- Convenient online submission

- Thorough peer review

- No space constraints or color figure charges

- Immediate publication on acceptance

- Inclusion in PubMed, CAS, Scopus and Google Scholar

- Research which is freely available for redistribution 